This is an Accepted Manuscript of an article published by Taylor \& Francis in Information, Communication \& Society on 23 November 2017, available online: http://www.tandfonline.com/10.1080/1369118X.2017.1406972

Recommended citation: Pacheco, E., Lips, M., \& Yoong, P. (2019). ICT-enabled selfdetermination, disability and young people. Information, Communication \& Society, 22(8), 1112-1127. https://doi.org/10.1080/1369118X.2017.1406972

\title{
ICT-enabled self-determination, disability and young people
}

\author{
Research and practice about self-determination in the context of disability has \\ centred on teaching skills and providing support to help people with impairments \\ to be independent. However, limited research exists about the impact of \\ Information and Communication Technologies, in particular social media and \\ mobile devices, on the development of self-determination skills among people \\ with disabilities. This paper presents the findings of a qualitative study which \\ collected data from observations, a researcher diary, focus groups, individual \\ interviews and data from social media. The focus of the study was on young \\ people with vision impairments who were transitioning to university life. The \\ study found that the participants developed self-determination skills by using and \\ adapting collaborative and interactive online tools and mobile devices according \\ to their transition needs. This finding expands the understanding of the \\ implications of new technologies for young people with disabilities' personal \\ development and the enhancement of self-determination.
}

Keywords: self-determination, Internet use, disability, ICTs, young adults, transition. 


\section{Introduction}

The transition to university is a critical period of change that has an impact on students' decisions to stay in or leave higher education (Tinto, 1993). Due to the barriers imposed by their impairments, young people with disabilities' transition experience is more challenging and stressful compared with their non-disabled peers (Winn \& Hay, 2009). Research shows that this group of students are more likely to give up university (Bardin \& Lewis, 2008) while those who persist spend more time studying at university before graduating (Caton \& Kagan, 2007).

In the field of education, promoting self-determination among young people with disabilities has been a significant area of research and practice. It is argued that self-determination supports students' success and their development as young adults (Wehmeyer \& Schwartz, 1997). Currently, the growing number of young people with disabilities enrolling in higher education around the world (Ebersold, 2008) is triggering interest in the way these students realise and develop themselves in the tertiary setting. In this respect, most research has focussed on providing tertiary institutions with best practices and guidelines for interventions that enhance students' self-determination (Wehmeyer \& Abery, 2013) so they can adjust and meet academic demands (Konrad, Fowler, Walker, Test, \& Wood, 2007).

However, while Information and Communication Technologies (ICTs) have become ubiquitous in society, little is known about what role ICTs play in the development of self-determination among students with disabilities and in the context of the transition experience. This is a relevant line of inquiry considering that the impact of ICTs on society is still a contentious issue. Some studies, especially those embracing the medical model of disability (Roulstone, 1998), outline the positive impact of assistive technologies (e.g. electronic braille) on the functional independence of people with disabilities (Stumbo, Martin, \& Hedrick, 2009). Past research suggests that ICTs can help people with intellectual and mobility disabilities in developing decision making skills (Cook et al., 2005) and a sense of empowerment (Tilley, 2009), respectively. Other studies also suggest that the use of the Internet increases people with impairments' perceptions of wellbeing (Barak \& Sadovsky, 2008) and independence (Grimaldi \& Goette, 1999).

A contrasting perspective is given by supporters of the social model of disability who warn about the oppressive and disabling nature of ICTs for people with disabilities (Goggin \& Newell, 2003) and the emergence of the disability divide (Dobransky \& Hargittai, 2006). Evidence shows that people experiencing disabilities have been excluded from online conversations, events and friendships (Carr, 2010), and experienced deception and been exposed to others' malevolent online behaviours (Bowker \& Tuffin, 2003). Some acknowledge that ICTs help to compensate for people's impairments but warn that there is a "high price" which is the reproduction of boundaries "between abled and disabled, and normal and deviant" (Moser, 2006, p. 373). Others (Adam \& Kreps, 2009; Ellcessor, 2010) argue that inequalities and exclusion arise when people with disabilities face issues such as web accessibility, high set-up costs, and inadequate technical support preventing the use of and access to technology. In a recent study, Alper (2017) argues that mobile devices also subject people with disabilities to "disempowering structural inequalities" (p. 3). While consensus about the role of ICTs is still pending, it seems that technology can have, as Tilley (2009) calls it, a double-edged sword effect on people with disabilities.

This article presents part of the findings of a qualitative study that looked at the transition experience of students with vision impairments and the role played by ICTs in this respect. Our study was guided by the tenets of constructivism (Guba \& Lincoln, 
1998) as we were interested in understanding participants' individual and collective construction of meaning about their transition experience and use of ICTs. The findings show that the different roles played by ICTs - including access to information, communication, collaboration and impairment compensation, among others - enabled students to acquire relevant knowledge and competencies to gradually become, to different extents, self-determined young adults.

\section{Background}

Concepts such as choice, control, independence, empowerment and selfdetermination are key in the literature about disability (Scott \& Doughty, 2012). Of these, self-determination has been particularly used in the context of education and young people (Field, Martin, Miller, Ward, \& Wehmeyer, 1998). Self-determination is broadly defined as "acting as the primary causal agent in one's life and making choices and decisions regarding one's quality of life free from undue external influence or interference" (Wehmeyer \& Schwartz, 1997, p. 246).

Self-determined people with disabilities share four main characteristics (Wehmeyer \& Schwartz, 1997). They are autonomous, self-regulated, psychologically empowered and self-realised. An autonomous person "acts according to his or her own preferences, interests and/or abilities, and independently, free from undue external influence or interference" (p. 246). A self-regulated individual can also make "decisions about which skills to use in a situation; examine the task at hand and their available repertoire; and formulate, enact, and evaluate a plan of action with revisions when necessary" (p. 246). A psychologically empowered person acts based on the beliefs that she or he has the capacity to perform behaviours needed to influence outcomes in their environment and, if they perform such behaviours, anticipated outcomes will result (pp. 246-247). Finally, a person with disability is self-realised when she or he uses "a comprehensive, and reasonably accurate, knowledge of themselves and their strengths and limitations to act in such a manner as to capitalize on this knowledge in a beneficial way" (p. 247).

Research highlights the importance of self-determination in the lives of people with disabilities. In the case of those who pursue tertiary education, interventions that enhance self-determination can help them to be actively involved in their transition planning (Test et al., 2004), perform better academically (Fowler, Konrad, Walker, Test, \& Wood, 2007), and, as a result, remain at university (Getzel \& Thoma, 2008). In the long term, self-determined students are likely to be employed at a higher rate earning more than their peers who are not self-determined (Wehmeyer \& Schwartz, 1997), and participate in community activities (Frankland, Turnbull, Wehmeyer, \& Blackmountain, 2004). In summary, developing self-determination can be a particularly relevant approach for young people as they are moving towards adulthood.

Literature has also drawn attention to other approaches to support and study how people with disabilities realise and develop themselves. The concept of interdependence (Condeluci, 1995), for example, points out the importance of relationships that lead to mutual acceptance and respect. While people have differences, they are also mutually dependent. Building and maintaining relationships enhance society's support and people with disabilities' participation in their communities (Condeluci, 1995). Interdependence relates to the concept of social capital (Putnam, 2000) which stresses the value of social networks and the norms of reciprocity and trustworthiness that arise from them. In Goggin and Newell's (2006) view, people's permanent use and adaption of ICTs 
provides practical understanding of interdependence and connectedness as new social forms.

\section{Method}

The research design was based on a qualitative action research (AR) method. AR was chosen for this study because it "aims to solve current practical problems while expanding scientific knowledge" (Baskerville \& Myers, 2004, p. 329). Considering that transition is a more challenging and stressful experience for students with disabilities, we used AR not only to expand current knowledge about this topic but also to support the participants to manage the practical challenges of their transition journey. We did so through online and face-to-face interventions which included setting up a website, a Facebook group, and group support meetings. In addition, AR is a method that is suited to the study of the interaction between people and technology (Baskerville \& WoodHarper, 1996). By using AR, we, the researchers, enhanced involvement and collaboration with and among the participants which helped them to make sense of and manage their transition experience.

The study involved two AR cycles. In cycle one, our intervention was to set up a website called Goingtouni via the Moodle platform. We choose the platform because of its user-friendly and accessibility features, its privacy safeguards and its collaborative tools. Goingtouni's content included transition-related information, links to YouTube videos, online forum and other resources. We included written content based on the advice of the University's Disability Services, available literature, and insights from our observations of participants' meetings with their Disability Advisor. The participants considered Goingtouni a useful source of information. However the website was unable to encourage interaction and collaboration among them.

We reflected on the limited impact of our first intervention and decided to implement new actions in the second AR cycle. We used the focus groups as group support meetings to help the students know each other. Through the meetings, the participants shared their transition experiences, provided support to each other and developed friendships and trust. The participants commented that the face-to-face meetings had a positive impact on helping them managing feeling of isolation and stress.

Following a suggestion from the participants, we also set up a Facebook closed group page which complemented face-to-face peer support and interaction originated through the group support meetings. Participants argued that Facebook was popular among their friends and peers, easy to use on mobile devices such as smartphones or tablets (all the participants owned at least one), and a convenient way to receive notifications automatically. The Facebook page became the preferred means of communication during the study while the Gointouni website was used as a repository of transition-related information and resources.

Research participants were selected purposefully. They were all students with vision impairments. All the participants were undergraduate students first enrolled at Victoria University of Wellington in trimesters 1 and 2, 2012, and trimester 1, 2013. They were in the age group of 18-24 years. In total, 19 participants took part in the study. Over a third of the participants came from Wellington and the rest from different cities and rural areas of New Zealand. In terms of schooling background, the participants came from varied educational systems such as special education schools, boarding schools and public schools where they had received dedicated teaching support. To understand the transition needs of the participants, one of the researchers 
also worked at the Disability Services as a research staff for 18 months. Access to the unit was critical to plan and implement interventions, and collect data.

Data gathering took place at different stages of the transition experience of the participants and included observations, a researcher diary, online tools, focus groups and semi-structured interviews. Once potential participants were contacted with the help of the Disability Services unit, the students were asked for permission to attend and observe their individual meetings with a Disability Advisor. These data were complemented with the use of a researcher diary which was employed to keep records, facilitate retrospective analysis, recall past thoughts and events, and evaluate the outcomes of the research (Borg, 2001).

Data from online tools were collected via a Moodle-based website and a Facebook group page. Participants' use of the website complemented the observations by helping to identify early transition issues. The second online tool for data collection, a Facebook group page, provided data in the form of online conversations, 'likes' and the 'seen by' feature on Facebook. While participants' online interaction via Facebook was mainly private, some online group conversations were enhanced which provided interesting insights about the impact of information sharing and collaboration on developing self-determination behaviour.

During the first AR cycle there was limited interaction and participation among the students. For this reason, three focus groups were organised in the second cycle of the study. Focus group data not only provided insights about the evolving perceptions of the participants about their transition but also signs of emerging self-determined behaviour over the academic trimester. Finally, semi-structured interviews were conducted after the participants completed their first trimester at university. The students reflected on their university experience, commented on how they used ICTs to manage challenges and, to different levels, demonstrated achievement of selfdetermination.

An inductive approach (Patton, 2002) was used for data analysis, which started in parallel with data collection. Transcripts with participant's comments were coded. We read, compared, and analysed several times the data to identify themes, to refine interpretations, and to allow categories to emerge. It was an ongoing and iterative process that helped to identify, for example, transition stages and the gradual development of self-determination. Quality and rigour of the study was ensured through the triangulation of various sources of data as described above. We included member checking by asking the participants to look at the transcripts of their interviews and sharing with them the main findings of the study. Peer debriefing was conducted with the two co-authors during data analysis and writing up of the study.

\section{Findings}

The findings are presented in five sub-sections that explain the different but overlapping stages of the transition experience of the research participants: exploring university as an option, discovering university life, coping with turning points, readjusting the transition experience, and settling in at university. One key finding is that the participants gradually developed self-determination by using and adapting a range of ICTs, particularly social media and mobile devices. Self-determination gradually developed in the weeks prior to and after their first academic trimester. While at the beginning the participants had a pro-active attitude towards being university students, they still lacked the knowledge and skills to manage the challenges of university life. At the end of the academic trimester, they learned, individually and 
collectively, how to cope with transition and gained skills to become independent young adults.

\section{Exploring}

At the beginning of the transition experience, the participants had not yet developed self-determined behaviour. During the exploring stage, a pre-entry period in which students explore tertiary education as a post-secondary option, the participants started wondering about what university life would be like, what challenges they might face once there, how their vision impairment might affect their tertiary experience and also what kind of support would be available for them.

The observation data allowed the identification of participants' early transitionrelated concerns and level of self-determination when they were still prospective students. Family involvement and availability of disability support were among the most important issues for the participants during this stage. The observation data also provided insights about participants' autonomy or the level to which they independently managed early transition-related activities and challenges (Wehmeyer \& Schwartz, 1997). For instance, prior to the start of the academic trimester the participants depended on and/or relied on their families and social connections to receive advice, decide what to study or contact university services.

In the exploring stage, the participants were still not self-realised - in other words they did not yet have a comprehensive and reasonably accurate knowledge of themselves and their strengths and limitations (Wehmeyer \& Schwartz, 1997, p. 246). For example, while their Disability Advisors recommended reducing course workload by enrolling in a small number of courses, the majority of participants ignored that advice and decided on full-time studies instead. They similarly overlooked the impact of their vision impairment on their transition. As a result, these participants later had to drop some courses when they found that their vision impairment was making it hard to manage university-related responsibilities. They were also not self-regulated students as they had not yet acquired the skills of an independent learner to face academic challenges.

In this stage, the role of ICTs for self-determination was limited. Most participants used technological tools to search for university-related information. A few students also used these tools to arrange disability support. In doing so, they started developing some level of autonomy (Wehmeyer \& Schwartz, 1997) regarding university life:

I looked out in the website and I got in touch with the Admission Office...I
wanted to find out what support is available for people with disabilities at Victoria University before I definitely came here. (VIS-CA)

Our AR intervention through Goingtouni confirmed participants' use of ICT tools primary for information seeking. They accessed the website to search links and resources about the University's physical environment, academic matters, and financial issues. Reflecting on her transition experience, a senior student, who took part in the pilot of the website, concurred with her peers about the role of the website to find relevant transition-related information: 
This is stuff that I have been looking for at the end of last year before coming to university... [U]sually we have to look at different websites or get booklets, different booklets, or find out all that stuff but it pretty much has a lot of stuff I was looking for last year on the website so I was like "this is cool". (VIS-GR)

\section{Discovering}

In this stage students are formally university students and start facing different transition issues in a real university context. It is a first-hand experience of university life. In this stage, rather than identifying and anticipating potential transition issues, the participants started experiencing them. Along with coping with the academic challenges, the students faced other issues such as physical environment and transportation. For all participants navigating around campus at the beginning of the trimester was challenging:

I have been lost on campus many times. I found myself walking around the same part many times [laughing]. (VIS-CA)

All the participants commented on having experienced pressure and anxiety, among other feelings, as a result of being new students. Also, they quickly realised how different university was from high school. One participant commented on the challenges of becoming an independent learner, especially handling the amount of course material provided to them. This participant was disoriented and summarised her frustration in this way:

I wish I would not finish high school because I don't know how to process information a little bit. (VIS-CA)

Another student agreed, pointing out how different the relationship between students and teaching staff at university is:

It is very different in the way the lecturers and tutors are involved. Teachers, they are like if your homework is due on Friday and you don't have it on Friday so they say: bring it on Monday or something. With lecturers and tutors, either, it is: bring it in or it is your fault and you deal with that. (VIS-GR)

There was still a way to go in terms of achieving self-determination for the participants. However, their use of ICTs helped them to manage early transition challenges, feel less stress and more confident. For example, some participants commented that in the first weeks of the academic trimester their mobile phone use of a PDF map of the accessible routes helped them to navigate around campus. Similarly, personal computers were useful to plan regular travel to the University and deal with transportation-related concerns: 
I learned to look for it [bus timetable] at home. I got my computer set to really large fonts so I can read it. So, I learned to do it at home before I take the bus. I can make my internet screen bigger so it makes it easier to read. (VIS-MO)

In this stage, ICTs also played a part in participants' initial development of selfregulation - the examination of one's environment and the repertoire of responses for coping with the challenges of that environment (Wehmeyer \& Schwartz, 1997). Some commented that through their personal email they let their lecturers know about their academic needs such as electronic copies of the lectures to be sent in advance or special arrangements for tutorials. These behaviours, which were supported by participants' use of ICTs, showed some level of decision-making and self-management which are inherent to self-regulation.

The participants did not limit themselves to one specific ICT tool to cope with their vision impairment, which they considered as a barrier for their transition. When facing academic duties their combined use of different ICTs helped them to minimise these challenges:

\section{I have OpenBook [a scanning and reading program], ZoomText [a magnification program] and I've also got a recorder to take to lectures as well... OpenBook and the recorder do help. I like OpenBook because I can look at the stuff that is there anyway and even if I am not reading it following it is enough. (VIS-CA)}

All the participants brought their laptops to lectures to support their learning experience. This behaviour is consistent with a growing tendency among university students in general who are using their personally owned portable devices to engage inside lectures (Gurung \& Rutledge, 2014).

As their peers without disabilities (Gikas \& Grant, 2013), the participants also employed social media and portable devices as a complementary environment for more informal and individualised learning. This use of ICTs supported formal learning which took place mainly in the physical settings of the University (lecture theatres, the library, study rooms, labs). For example, YouTube was used by some participants through their laptops and mobile phones for "big study". The students used the video-streaming platform to complement what was taught by the lecturer in class and/or search for further information about the essay topic they had to write about. In both cases, students with vision impairments adapted social media to respond to their personal learning needs.

\section{Coping with turning points}

This stage involves critical life events and/or experiences that have an impact on the transition to university, to the extent that the students experience changes and/or 
acquire new meanings. Turning points represent a significant shift regarding the self, identity and the meaning and/or direction of a person's life (Wethington, 2003). Turning points involve the way the students manage those significant life events or situations as well as the resources and tools they use to support their responses.

In this study, participants were more likely to feel the impact of academicrelated turning points. Two of them commented that they considered quitting university because academic responsibilities were too demanding and their vision impairments were making things more challenging. Participants also outlined the impact of turning points based on non-university situations (e.g. the difficulties of making new social connections, the need for suitable accommodation and/or financial constraints).

Turning points had, at the end, positive implications for the participants as they were a catalyst for personal growth and understanding of the transition experience. Participants kept developing some elements of self-determined behaviour, such as selfregulation and self-realisation. They evaluated the events causing turning points, used their personal available repertoire and knowledge, and took actions to deal with them.

ICTs played a relevant part in managing critical events. When facing a social connection-related turning point, the participants used a range of ICTs to maintain existing social connections and/or build new ones. They used their laptops, personal computers, smartphones, and applications such as Skype to communicate and seek support from high school friends and complement or supplement face-to-face interactions. Consistent with prior research on disability (Shpigelman \& Gill, 2014), social media also helped the participants to create new connections between them. The group page set up on Facebook for this study was also a means to deal with turning points related to the lack of social connections.

\section{I actually made friends with a lot of them [participants] on Facebook and we} actually talk quite often now. I talk with X a lot. He likes me on Facebook all the time. I talk with a lot of them. I had never met them outside of the group. I made new friends through the group and it was very helpful just asking people in the group about stuff. (VIS-MO)

ICTs also supported students to manage academic-related turning points. The majority of participants mentioned Blackboard, the University's course management system, as one of the tools used to deal with academic challenges. Although some students struggled with the platform at the beginning, once they were used to it Blackboard became the primary source of academic information and resources and to some extent study-related online interaction. One participant, who was in trouble after failing two of her assignments for the same course, commented that she used the forum feature of the platform to post questions and receive feedback from her classmates about writing assignments.

Another participant was pleased about the way some university teaching staff used social media to encourage collaboration among students. She mentioned that closed groups were set up on Facebook by her lecturer or, in other cases, by class representatives. Being able to "talk with other students" online was a positive experience that supported her in managing different academic challenges.

The online group set up for this study via Facebook was also an additional tool to manage turning points. Information and links posted on the Facebook group sought to foresee potential transition issues. They were selected based on the concerns expressed 
by the participants during the focus groups. All the participants commented that the posts were useful. One student, for example, mentioned the handouts about writing essays in PDF format and the links to service units such as the Student Learning Support Service which she contacted for advice about developing study skills. In summary, ICTs clearly supported students' actions to cope with critical events affecting their transition journey.

\section{Readjusting}

This stage refers to students' actions to readjust their transition based on new information, elements and contexts resulting principally, but not only, from coping with turning points. It involves making decisions. While in the preceding stages they have been, little by little, refining their understanding of transition, in the readjusting stage they obtain a more straightforward and enriched picture of it. The impact of both positive and negative turning points mainly triggers such understanding. As a result the participants start considering and adopting new directions, but also, in some cases, reaffirming previous ones. This does not mean that decisions are only adopted in the readjusting stage. As described in the previous subsections, making decisions and taking actions has been a recurrent practice among the participants even before their formal arrival at university, but with a focus on their immediate transition challenges and needs.

In the readjusting stage new directions are taken in order to improve the rest of the transition experience for the academic year and/or the university journey as a whole. Such new decisions are strongly related to the academic system issue in connection with the challenges of their vision impairments. Dropping one paper to reduce course workload for the rest of the first trimester was one such decision. Another was changing their enrolment status from full-time to part-time in the next academic trimester. Interestingly, while dropping out of university was considered in some cases as an immediate response to turning points, none of the participants decided to leave university as a consequence of academic-related challenges.

The development of self-determined behaviour among the participants becomes more apparent in the readjusting stage. By analysing and making decisions that will have an impact on the rest of their transition and university experience, several students showed self-regulation and autonomy as they gained a better understanding of their own strengths and limitations. The decision made by one participant in relation to course workload in trimester 2 describes this point:

I'm doing two papers this trimester which is probably what I should have done in trimester one just to ease myself into university. (VIS-GR)

Being autonomous is also a feature of self-determined behaviour. In this respect another participant showed the ability to take a new direction based on his own interests by changing his course timetable for the following trimester:

I am certainly doing it [Law degree]. I'm just putting it off for next year. So when most people do Law papers in the first three years and do the BA papers for last year, for a four-year degree, I am doing the other way round. (VIS-GE) 
ICTs also enhanced participants' development of self-determined behaviour during the readjusting stage. These tools supported the students in making informed decisions. ICTs were used to search for information and to follow formal administrative steps regarding managing their programme of study. Some participants commented that, for example, they accessed the University's website and looked for information about other study options as well as administrative procedures to change their degree and/or courses. They used the website to find out more about the requirements of the courses they planned to enrol in, access downloadable forms, and ask university staff for pertinent information, if needed. ICTs were also another medium through which the participants were able to make administrative changes related to their programme of study. Changes of degree, major or enrolment status were also possible online via myVictoria, the University's web portal. The participants did not report any accessibility issues with the portal.

Social media and mobile devices were another means used to search for information. In the last weeks of the academic trimester links and resources from the University's social media were re-posted on the Facebook group page to remind the participants about some deadlines such as course change applications. Most participants commented that the links were useful and helped them to realise that the University also had a presence on social media platforms which they started following too.

\section{Settling in}

In the last stage of the transition to university, self-determination is more manifest. In this stage the participants find themselves reaching, on their own terms, familiarisation and a sense of control of their university experience and its demands. Settling in is a stage of relative stability. It contrasts with previous transition stages in which anxiety, insecurity, and/or loneliness are common feelings; in the settling-in stage the participants are more confident and secure about their transition experience, including the prospects of their university journey.

The settling-in stage does not mean that transition challenges are finally over. These challenges remain but, on average, they are perceived as manageable. The participants are aware that different issues will still be challenging for them throughout their entire university journey. They understand, for instance, that assignments and essays still have to be written but in contrast with the first weeks of trimester 1, they now know how to approach them. They are more confident with lectures and tutorials, but also conscious that they still need the support of a note-taker and special arrangements for final exams (e.g. extra time or a special room).

The perception of being 'settled in' comes at the beginning of trimester 2 in most cases. In contrast with the first trimester, the participants are now used to the university environment, feel better prepared and more confident to handle the challenges. One student, who thought about dropping out of university in trimester 1, reflected on how different things were in trimester 2 :

It is just a better feeling now in second trimester. It doesn't feel like I'm still doing first year. It feels like I am in second year. There is much more work than it was last trimester... but I feel better now. I am in second trimester and my grades have jumped a lot. I wouldn't say they are pretty easy. I just get used to 
the way the lectures and assignment work. When I first came I was like 'wow, what's happening?', 'I did not catch that, what do I do?' but now I am more than adjusted; I know how to do [things] properly. (VIS-MO)

Settling in at university suggests the development of a sense of belonging (Hoffman, Richmond, Morrow, \& Salomone, 2002, p. 28). University is no longer perceived as an odd place. On the contrary, as the participants understand transition, university is perceived, to a lesser or greater extent, as a place they are part of. Once some degree of familiarisation and confidence is achieved, the participants were keen to share their transition experiences and act as insiders. Although they may not know all about university life and will still be learning about it through their whole time at university, the participants have accumulated enough expertise to help other future students with vision impairments. The sense of empowerment and independence are clear characteristics of self-determined behaviour:

I think I have gained that notion of independence; it is the concept, you know, 'oh, I need to go to the shops I just walk out the door and go over'. It is not 'I wait for mum to get the car, swift and go'. It is that notion that I am now in charge, I am the master of my destiny...I would say, probably, it is just the simple acknowledgment that I know how to do things. I think that in that respect I have become a little bit more assertive in getting things organised. (VIS-GE)

All the participants agreed that ICTs played a role in helping them make sense of transition, and gradually develop self-determination. Even one participant, VIS-BR, who approached the Disability Services a few weeks after the start of the academic trimester and was still "finding me feet", developed, to some degree, self-determination. Along other participants, he considered himself as "ICT savvy" and used his skills to find online accessible accommodation or information on YouTube to complement lectures. In addition to supporting transition, all the participants concurred that ICTs offer more advantages than disadvantages for young people with impairments:

Technology, I think, is one of the biggest helps out there for anyone with a disability. It makes it easier for you to access things. It makes it a lot easier for you to communicate with people, who you need to communicate with, Disability Advisor, Course Coordinator or something like that. It is just easier than going on foot to meet everyone. (VIS-JO)

The individual interviews with the participants confirmed the role of ICTs for the development of self-determination. Comments about becoming autonomous through the support of ICTs were common among them. For instance, some participants mentioned that using their laptops or mobile phones to plan their bus journey made 
them feel more independent. There was consensus in their responses that ICTs made transition easier. They also gained the sense of being independent learners when they became familiar with Blackboard and used YouTube through their laptops, tablets and/or smartphones to manage their course workload and support their learning. These findings contribute, from the context of disability, to the understanding of personal learning environments which are learning approaches based on different types of tools/content (e.g. videos, apps, games and social media) chosen by the student to match her or his personal learning style and pace (Johnson, Adams, \& Haywood, 2011). One participant, for instance, pointed out that academic staff do not understand the way students with impairments use ICTs to support studying and learning:

For one of my courses we used a workbook and the lecturer originally offered to copy it from the size it was to size A3. So, that would mean 'oh, yeah, I will be carrying around a massive A3 book' and trying to do my work on that, which is crazy for anybody...I will never go back [to paper-based books]. I managed to get the entire workbook emailed to me so I could work on it on my laptop. (VIS$C A)$

Assistive technologies such as digital voice recorders, note-taking devices, and magnifying and text-to-speak computer programs also supported the transition experience of the participants. In many cases, assistive technologies were used in conjunction with other ICTs such as laptops and mobile phones:

Usually it takes half an hour to read a page. By using the technology that the university provides me, it takes me ten minutes to read it because it is really quick and fast and I am not tired afterwards which is really good because usually after reading something I have to go for a 20-minutes break to recharge and feel better again. With CCTV it is like 'ah, I am not tired; let's read something else'. (VIS-MO)

In addition to the perception of being autonomous, the participants also saw themselves as achieving self-regulation. They became self-regulated students when they commented on being able to make their own decisions and readjust their university journey by changing their major or their enrolment status to part-time. As previously mentioned, they did so with the support of ICTs which were used to access relevant information and establish adequate support. The participants also saw themselves as psychologically empowered. Their sense of control was expressed not only in the belief that they had become the masters of their destiny but also in the idea that, despite it still being a difficult journey, the challenges of transition were manageable.

Self-realisation was also identified in the interview data. For instance, the majority of participants recognised that they had initially underestimated not only the constraints imposed by their impairments but also by the university setting itself which they had thought would be like high school. This realisation implied a better understanding of their own weaknesses. In this sense, the participants commented on 
how assistive technology and the accessibility features of their mobile devices helped them to compensate for their impairment. By using ICTs to communicate and collaborate with their peers and manage academic responsibilities, the participants were able to settle in at university and re-affirm or readjust their personal and academic goals. For example, some participants decided to change their majors because they had a better understanding of their personal skills and interests.

Data from online tools, particularly the Facebook group, also expanded the understanding of participants' transition experience and the development of ICTenabled self-determination. The data revealed that the students were supporting each other, interacting and collaborating through the social media platform to manage different transition challenges. As they coped with these challenges, the participants were feeling more in control of transition, and, thus, psychologically empowered (Wehmeyer \& Schwartz, 1997). Through the Facebook group, they shared, for example, tips and gave each other advice about how to spend money wisely. While learning how to manage financial challenges, the participants were also building trust and friendship, and complemented this by becoming Facebook friends. As a result, their use of social media helped them to deal with the social connection issue which was one of the main causes of turning points among several participants. These findings are consistent with previous research about social media supporting the formation and maintenance of social capital among university students in general (Ellison, Steinfield, \& Lampe, 2007).

When I am in my room I open my Facebook and sometimes I find my friends saying: 'oh, come to the study lounge tonight. We miss you. Come to hang out'. So I pick up my stuff. I go down there and study with them all night as well as socialising. More socialising goes on when studying but I still get a heap of work done. (VIS-MO).

\section{Discussion and Conclusions}

This study has shown that students with vision impairments can develop selfdetermination with the support of a range of ICTs. In doing so, they not only learn how to cope with the challenges of transition to university but also how to gain the skills and behaviour of independent young adults. By using and adapting ICTs, the participants gradually acquired self-determined competencies. They not only perceived themselves as but also demonstrated having achieved different levels of autonomy, empowerment, self-regulation and self-realisation. In the early stages of their transition they showed a strong motivation to pursue a tertiary degree. However, in addition to the constraints imposed by their vision impairments, they lacked the skills and knowledge to manage different transition challenges. They were also feeling isolated and stressed. To cope with the demands of transition, they used and adapted ICTs innovatively for diverse purposes: communication, information, learning, vision compensation, collaboration and peer support among others. When the students reached the last stages of transition they had already gained confidence and familiarity with the university environment. Apart from academic responsibilities, the students' use of ICTs helped them to acquire the required skills and knowledge to manage critical life events and see themselves as independent young adults. 
Therefore, there is a new scenario triggered by the use of ICTs that challenges the way self-determination is encouraged in students with disabilities transitioning to university. Currently, the focus is on teaching self-determination skills, recommending best practices and evaluating the effectiveness of self-determination programmes so students can manage academic issues and remain at university. While teaching skills is helpful, we also need to look at the dynamic of the strong interaction between ICTs and students with vision impairments to understand additional and/or complementary ways of developing self-determination. The implications of this study for research and practice are that future research on self-determination and the delivery of specialised support services need to consider how creatively young people with disabilities interact with ICTs to cope with vision-related and everyday-life challenges. Researchers and practitioners from fields such as disability, special education and rehabilitation can benefit from these new insights and incorporate them in future studies and the implementation of support services.

This study has some limitations. The main one is its highly contextual nature. Thus, it may not be applicable in other tertiary education settings. However, its findings can be used as a lens for further study of the role of ICTs in tertiary environments such as polytechnics and colleges as well as the transition experience of other disability groups. Uncovering the context of ICT-enabled self-determination also opens opportunities for future avenues of research. Scholars may want to study ICT-enabled self-determination in the context of career development and transition to work of school leavers with disabilities. 


\section{References}

Adam, A., \& Kreps, D. (2009). Disability and discourses of Web accessibility. Information, Communication \& Society, 12(7), 1041-1058. doi: 10.1080/13691180802552940

Alper, M. (2017). Giving voice: Mobile communication, disability, and inequality. London: MIT Press.

Barak, A., \& Sadovsky, Y. (2008). Internet use and personal empowerment of hearing-impaired adolescents. Computers in Human Behavior, 24(5), 1802-1815.

Bardin, J. A., \& Lewis, S. (2008). A survey of the academic engagement of students with visual impairments in general education classes. Journal of Visual Impairment \& Blindness, 102(8), 472-483.

Baskerville, R., \& Myers, M. (2004). Special Issue on action research in information systems: Making IS research relevant to practice: Foreword. MIS Quarterly, 28(3), 329-335.

Baskerville, R., \& Wood-Harper, A. T. (1996). A critical perspective on action research as a method for information systems research. Journal of Information Technology, 11, 235-246.

Borg, S. (2001). The research journal: A tool for promoting and understanding researcher development. Language Teaching Research, 5(2), 156-177.

Bowker, N., \& Tuffin, K. (2003). Dicing with deception: People with disabilities' strategies for managing safety and identity online. Journal of ComputerMediated Communication, 8(2). http://jcmc.indiana.edu/vol8/issue2/bowker.html

Carr, D. (2010). Constructing disability in online worlds: Conceptualising disability in online research. London Review of Education, 8(1), 51-61.

Caton, S., \& Kagan, C. (2007). Comparing transition expectations of young people with moderate learning disabilities with other vulnerable youth and with their non-disabled counterparts. Disability \& Society, 22(5), 473-488.

Condeluci, A. (1995). Interdependence: The route to community. Boca Raton: CRC Press.

Cook, J. A., Fitzgibbon, G., Batteiger, D., Grey, D. D., Caras, S., Dansky, H., \& Priester, F. (2005). Information technology attitudes and behaviors among individuals with psychiatric disabilities who use the Internet: Results of a web-based survey. Disability Studies Quarterly, 25(2), N.PAG.

Dobransky, K., \& Hargittai, E. (2006). The disability divide in internet access and use. Information, Communication \& Society, 9(3), 313-334.

Ebersold, S. (2008). Adapting higher education to the needs of disabled students: Developments, challenges and prospects. In OECD (Ed.), Higher education to 2030 (pp. 221-240). Paris: OECD Publishing.

Ellcessor, E. (2010). Bridging disability divides: A critical history of web content accessibility through 2001. Information, Communication \& Society, 13(3), 289-308. doi: 10.1080/13691180903456546

Ellison, N. B., Steinfield, C., \& Lampe, C. (2007). The benefits of Facebook "friends:" Social capital and college students' use of online social network sites. Journal of Computer-Mediated Communication, 12(4), 1143-1168.

Field, S., Martin, J., Miller, R., Ward, M., \& Wehmeyer, M. (1998). A practical guide for teaching self-determination. Reston, Virginia: ERIC.

Fowler, C. H., Konrad, M., Walker, A. R., Test, D. W., \& Wood, W. M. (2007). Self-determination interventions' effects on the academic performance of 
students with developmental disabilities. Education and Training in Developmental Disabilities, 42(3), 270-285.

Frankland, H. C., Turnbull, A. P., Wehmeyer, M., \& Blackmountain, L. (2004). An exploration of the self-determination construct and disability as it relates to the Dine (Navajo) culture. Education and Training in Developmental Disabilities, 39(3), 191-205.

Getzel, E. E., \& Thoma, C. A. (2008). Experiences of college students with disabilities and the importance of self-determination in higher education settings. 31(2), . Career Development for Exceptional Individuals, 31(2), 77-84. doi: 10.1177/0885728808317658

Gikas, J., \& Grant, M. M. (2013). Mobile computing devices in higher education: Student perspectives on learning with cellphones, smartphones \& social media. The Internet and Higher Education, 19, 18-26. doi: http://dx.doi.org/10.1016/j.iheduc.2013.06.002

Goggin, G., \& Newell, C. (2003). Digital disability: The social construction of disability in new media. Oxford: Rowman \& Littlefield Publishers.

Goggin, G., \& Newell, C. (2006). Editorial comment: Disability, identity, and interdependence: ICTs and new social forms. Information, Communication \& Society, 9(3), 309-311. doi: 10.1080/13691180600751272

Grimaldi, C., \& Goette, T. (1999). The Internet and the independence of individuals with disabilities. Internet Research, 9(4), 272-280. doi: $10.1108 / 10662249910286743$

Guba, E. G., \& Lincoln, Y. S. (1998). Competing paradigms in qualitative research. In N. K. Denzin \& Y. S. Lincoln (Eds.), The landscape of qualitative research: Theories and issues (pp. 195-220). Thousand Oaks: SAGE Publications.

Gurung, B., \& Rutledge, D. (2014). Digital learners and the overlapping of their personal and educational digital engagement. Computers \& Education, 77, 91-100. doi: 10.1016/j.compedu.2014.04.012

Hoffman, M., Richmond, J., Morrow, J., \& Salomone, K. (2002). Investigating "sense of belonging" in first-year college students. Journal of College Student Retention: Research, Theory \& Practice, 4(3), 227-256.

Johnson, L., Adams, S., \& Haywood, K. (2011). The NMC Horizon Report: 2011 K-12 Edition. Austin, Texas: The New Media Consortium.

Konrad, M., Fowler, C. H., Walker, A. R., Test, D. W., \& Wood, W. M. (2007). Effects of self-determination interventions on the academic skills of 
students with learning disabilities. Learning Disability Quarterly, 30(2), 89-113.

Moser, I. (2006). Disability and the promises of technology: Technology, subjectivity and embodiment within an order of the normal. Information, Communication \& Society, 9(3), 373 - 395.

Patton, M. Q. (2002). Qualitative research \& evaluation methods (Third ed.). Thousand Oaks: SAGE Publications.

Putnam, R. D. (2000). Bowling alone: The collapse and revival of American community. New York: Simon \& Schuster.

Roulstone, A. (1998). Enabling technology: Disabled people, work, and new technology. Buckingham: Open University Press.

Scott, A., \& Doughty, C. (2012). Care, empowerment and self-determination in the practice of peer support. Disability \& Society, 27(7), 1011-1024.

Shpigelman, C. N., \& Gill, C. J. (2014). Facebook use by persons with disabilities. Journal of Computer-Mediated Communication, 19(3), 610624.

Stumbo, N. J., Martin, J. K., \& Hedrick, B. N. (2009). Assistive technology: Impact on education, employment, and independence of individuals with physical disabilities. Journal of Vocational Rehabilitation, 30(2), 99-110.

Test, D. W., Mason, C., Hughes, C., Konrad, M., Neale, M., \& Wood, W. M. (2004). Student involvement in individualized education program meetings. Exceptional Children, 70(4), 391-412.

Tilley, C. M. (2009). A sense of control: Virtual communities for people with mobility impairments. Oxford: Chandos Publishing.

Tinto, V. (1993). Leaving college: Rethinking the causes and cures of student attrition (Second ed.). Chicago: University of Chicago Press.

Wehmeyer, M., \& Abery, B. H. (2013). Self-determination and choice. Intelectual and Developmental Diabilities, 51(5), 399-411. doi: 10.1352/1934-955651.5.399

Wehmeyer, M., \& Schwartz, M. (1997). Self-determination and positive adult outcomes: A follow-up study of youth with mental retardation or learning disabilities. Exceptional Children, 63(2), 245-255.

Wethington, E. (2003). Turning points as opportunities for psychological growth. In C. L. Keyes \& J. Haidt. (Eds.), Flourishing: positive psychology and the life well-lived (pp. 37-53). Washington, DC: American Psychological Association.

Winn, S., \& Hay, I. (2009). Transition from school for youths with a disability: issues and challenges. Disability \& Society, 24(1), 103-115. 